\title{
Non-ionic surfactant vesicles simultaneously enhance antitumor activity and reduce the toxicity of cantharidin
}

This article was published in the following Dove Press journal:

International Journal of Nanomedicine

13 June 2013

Number of times this article has been viewed

\author{
Wei Han ${ }^{1, *}$ \\ Shengpeng Wang ${ }^{2, *}$ \\ Rixin Liang' \\ Lan Wang' \\ Meiwan Chen² \\ Hui Li' \\ Yitao Wang ${ }^{1,2}$ \\ 'Institute of Chinese Materia Medica, \\ China Academy of Chinese Medical \\ Sciences, Beijing, People's Republic \\ of China; ${ }^{2}$ State Key Laboratory \\ of Quality Research in Chinese \\ Medicine, Institute of Chinese Medical \\ Sciences, University of Macau, \\ Macau, People's Republic of China \\ *These authors contributed equally \\ to this work
}

Objective: The objective of the present study was to prepare cantharidin-entrapped non-ionic surfactant vesicles (CTD-NSVs) and evaluate their potential in enhancing the antitumor activities and reducing CTD's toxicity.

Methods and results: CTD-NSVs were prepared by injection method. 3-(4,5-Dimethylthiazol-2-yl)-2,5-diphenyltetrazolium bromide assay and flow cytometry analysis showed that CTD-NSVs could significantly enhance in vitro toxicity against human breast cancer cell line MCF-7 and induce more significant cell-cycle arrest in G0/G1 phase. Moreover, Hoechst 33342 staining implicated that CTD-NSVs induced higher apoptotic rates in MCF-7 cells than free CTD solution. In vivo therapeutic efficacy was investigated in imprinting control region mice bearing mouse sarcoma $\mathrm{S}_{180}$. Mice treated with $1.0 \mathrm{mg} / \mathrm{kg}$ CTD-NSVs showed the most powerful antitumor activity, with an inhibition rate of $52.76 \%$, which was significantly higher than that of cyclophosphamide (35 mg/kg, 40.23\%) and the same concentration of free CTD $(1.0 \mathrm{mg} / \mathrm{kg}$, $31.05 \%$ ). In addition, the acute toxicity and liver toxicity of CTD were also distinctly decreased via encapsulating into NSVs.

Conclusion: Our results revealed that NSVs could be a promising delivery system for enhancing the antitumor activity and simultaneously reducing the toxicity of CTD.

Keywords: cantharidin, non-ionic surfactant vesicle, toxicity, antitumor activity

\section{Introduction}

Blister beetles (Mylabris phalerata) have been used as a traditional medicine for more than 2000 years. ${ }^{1}$ These dried insect bodies are traditionally employed in the People's Republic of China to treat warts and mollusca through topical administration. ${ }^{2,3}$ Cantharidin (CTD), the major bioactive compound in Mylabris, exists in all body fluids, and its antitumor activity has been long acknowledged. ${ }^{2}$ The potential of CTD has been thoroughly elucidated, and its antitumor effect is considered primarily due to its potently and selectively inhibitive ability on serine/threonine protein phosphatases 1 and $2 \mathrm{~A} .{ }^{4}$ Inhibition of protein phosphatases has been shown to regulate multiple cellular processes, through which CTD triggers G0/G1 or G2/M arrest ${ }^{5,6}$ and apoptosis mediated by the mitochondrial caspase cascade. ${ }^{7}$ Moreover, CTD has been shown to increase the level of Bax, inhibit the expression of B-cell lymphoma 2 and survivin, ${ }^{8}$ and regulate the production of reactive oxygen species, subsequently inducing apoptotic cell death. ${ }^{9}$ However, the toxicity of CTD, including the damage to mammals' urinary system, hematemesis, dysuria, liver congestion, and the risk of aborticide, remains a great challenge for its further development in clinical applications. ${ }^{1}$ Therefore, scientists have persisted in the search to maximize its potential, and many CTD 
derivatives and several novel drug-delivery systems have been developed. ${ }^{10-13}$

Non-ionic surfactant vehicles (NSVs), the so-called niosomes, have attracted major attention as a new drugdelivery system in the pharmaceutical field since the late 1980s. As an alternative approach to the conventional liposomal devices, NSVs are formed by the self-assembly of non-ionic amphiphiles in aqueous media, resulting in closed spheroidal structures. They have been proposed for both topical and systemic administration. ${ }^{14-16}$ Several studies have demonstrated that NSVs behave like liposomes in vivo. They do so by prolonging the circulation of entrapped drugs, minimizing drug degradation and inactivation after administration, preventing undesirable side effects, increasing drug bioavailability, and targeting the pathological area. ${ }^{15,17,18}$ Therefore, we were interested in using CTD-encapsulated NSVs to enhance its antitumor activity and decrease its toxicity. In the present study, we prepared CTD-loaded NSVs (CTD-NSVs) by injection method, and the antitumor activity of CTD-NSVs was evaluated both in vitro and in vivo.

\section{Materials and methods Experimental agents}

CTD was extracted and purified from Blister beetles (Mylabris phalerata); purity was over $98 \%$, as determined by high-performance liquid chromatography. The CTD preparation was made by dissolving in dimethyl sulfoxide at a stock concentration of $100 \mathrm{mM}$. Cyclophosphamide was obtained from Jiangsu Hengrui Medicine (Lianyungang, People's Republic of China). Span 40 and Tween 80 were purchased from Sinopharm Chemical Reagent (Shanghai, People's Republic of China) and Guangzhou Huarui Chemical Instrument (Guangzhou, People's Republic of China), respectively. Fetal bovine serum, phosphate-buffered saline (PBS), penicillin-streptomycin, $0.25 \%(\mathrm{w} / \mathrm{v})$ trypsin/1 mM ethylenediaminetetraacetic acid, Hoechst 33342 , and propidium iodide (PI), and 3-(4,5-dimethylthiazol-2-yl)-2,5-diphenyltetrazolium bromide (MTT) were purchased from Life Technologies (Carlsbad, CA, USA). Other chemicals were of analytical grade from local sources and used without further purification. An alanine aminotransferase (ALT) assay kit, $\gamma$-ammonia acyltransferase (AST) assay kit, and total bilirubin (TBIL) assay kit were provided by Beijing Beihua Kangtai Clinical Reagent (Beijing, People's Republic of China). The $\mathrm{S}_{180}$ tumor strain was supplied by the Experimental Animal Center of the Institute of Chinese Materia Medica, China Academy of Chinese Medical Sciences.

\section{Preparation and characterization of CTD-loaded non-ionic surfactant vesicles}

CTD-NSVs were prepared by an injection method described previously. ${ }^{19}$ Briefly, a predetermined amount of CTD, Span 40/Tween $80(1: 1 \mathrm{w} / \mathrm{w})$ and cholesterol in a mass ratio of 5:1 were dissolved in an aliquot of diethyl ether. The obtained organic solution was added drop-wise into 10 times volume of distilled water under vigorous stirring. The system was stirred at room temperature overnight to make the drug participate into the capsule wall. The prepared CTD-NSVs were characterized on the basis of their size $(209.8 \pm 0.5 \mathrm{~nm})$, morphology by transmission electron microscope (TEM), polydispersity index (0.331), zeta potential $(-27.3 \pm 2.9 \mathrm{mV})$, and total drug-loading capacity $(0.6 \pm 2.0 \mathrm{mg} / \mathrm{mL})$.

\section{Cells and animals}

The breast cancer cell line MCF-7 was obtained from the American Type Culture Collection. Cells were cultured in Roswell Park Memorial Institute 1640 medium supplemented with antibiotics $(100 \mathrm{U} / \mathrm{mL}$ penicillin and $100 \mu \mathrm{g} / \mathrm{mL}$ streptomycin) and $10 \%(\mathrm{v} / \mathrm{v})$ heat-inactivated fetal bovine serum at $37^{\circ} \mathrm{C}$ under $5 \% \mathrm{CO}_{2}$.

Kunming SPF mice (composed equally of male and female for acute toxicity testing and male for the liver toxicity experiment, 18-28 g) were bred under regular laboratory conditions (ie, room temperature and natural light-dark cycle) for 1 week before study, with free access to standard rodent chow and water. ICR male mice ( $20 \pm 2 \mathrm{~g}$ ) were purchased for the solid-tumor experiment. All mice were purchased from the Experimental Animal Center of the Academy of Military Medical Sciences (license number SCXK [Army] 2007-004). All of the animal experiments were performed in full compliance with guidelines approved by the Animal Care Committee at the China Academy of Chinese Medical Sciences (Beijing, People's Republic of China).

\section{In vitro cytotoxicity studies}

Cell viability was estimated by MTT assay, as described previously. ${ }^{20-22}$ MCF-7 cells were seeded at a density of 8000 cells per well into a 96-well plate and allowed to attach overnight. After reaching approximately $70 \%-80 \%$ confluence, the cells were starved by incubation with a serum-free medium for 24 hours. Then, the cells were treated with different concentrations of blank NSVs, free CTD and CTD-NSVs for 24 and 48 hours, respectively. Cell viability was then determined by incubation with medium containing MTT $(1 \mathrm{mg} / \mathrm{mL})$ for 4 hours. After removal of the medium, the formazan crystals were dissolved in $100 \mu \mathrm{L}$ 
dimethyl sulfoxide. Absorbance at $570 \mathrm{~nm}$ was determined with a microplate reader and presented as relative cell viability. Percentage of cell survival was defined as the relative absorbance of treated cells versus respective controls.

\section{Cell-cycle analysis}

Cell-cycle distribution based on DNA content was determined as previously described. ${ }^{23,24} \mathrm{MCF}-7$ cells were seeded at a density of $5.0 \times 10^{5}$ cells into a $25 \mathrm{~mL}$ Nunc (Thermo Fisher Scientific, Waltham, MA, USA) cell-culture flask and allowed to attach overnight. After being starved by incubation with a serum-free medium for 24 hours, cells were treated with different concentrations of blank NSVs, free CTD, and CTD-NSVs for another 24 hours. After being washed twice with PBS, cells were trypsinized and harvested by centrifugation at $500 \mathrm{~g}$ for 5 minutes, followed by fixing in ice-cold $70 \%$ ethanol (v/v) at $-20^{\circ} \mathrm{C}$ overnight. Subsequently, cells were collected by centrifugation and stained with $100 \mu \mathrm{L}$ of $\mathrm{PI} /$ ribonuclease staining solution $(20 \mu \mathrm{g} / \mathrm{mL}$ PI and $8 \mu \mathrm{g} / \mathrm{mL}$ ribonuclease, respectively) for 30 minutes (protected from light), then analyzed by a flow cytometer (BD FACS Canto, BD Biosciences, San Jose, CA, USA). The cell distribution of sub-G1, G0/G1, S, and G2/M were measured, and results were calculated using ModFit LT software (Version 3.0, Verity Software House, Topsham, ME, USA).

\section{Apoptotic cell determination by Hoechst 33342 staining}

Apoptotic nuclear morphology was assessed by Hoechst 33342 staining. ${ }^{25} \mathrm{MCF}-7$ cells were seeded in 24-well plates at a density of $1.0 \times 10^{5}$ per well. After 24 hours of incubation, cells were treated with blank NSVs, free CTD and CTD-NSVs $(0,20 \mu \mathrm{M})$. After 48 hours' incubation, cells were fixed with $4 \%$ paraformaldelyde for 30 minutes at room temperature, then washed with PBS and stained with $1 \mu \mathrm{g} / \mathrm{mL}$ of Hoechst 33342 at room temperature for 30 minutes. Photographs of apoptotic nuclear morphology were taken by a fluorescent microscope (Olympus, Tokyo, Japan). Apoptotic cells were distinguished through their characteristic patterns of cytoplasmic rounding, membrane blebbing, and nuclear condensation.

\section{Antitumor efficacy in vivo}

In vivo anticancer activity was evaluated in $\mathrm{S}_{180}$ tumorbearing mice. ICR male mice were inoculated subcutaneously with $\mathrm{S}_{180}$ cells at a density of $1 \times 10^{7} / \mathrm{mL}$ in PBS. The dose schedule started 24 hours after tumor cell transplantation with the aim of mimicking the early stage of tumor growth. ${ }^{26}$ The inoculated mice were assigned randomly to four groups: control, cyclophosphamide, CTD, and CTD-NSVs. The mice were treated with saline, cyclophosphamide (35 mg/kg), free CTD $(0.25,0.5$, and $1 \mathrm{mg} / \mathrm{kg})$ and CTDNSVs $(0.25,0.5$, and $1 \mathrm{mg} / \mathrm{kg})$, respectively. The size of the tumor was recorded every 10 days. Mice were killed when tumor sizes in the control group were $2 \mathrm{~cm}^{3}$ (ie, 28 days after cell inoculation). The tumor and other organs were surgically removed for measurement of mouse weight, tumor weight, spleen and thymus index (spleen/thymus index $=$ the final weight of spleen/thymus [mg] of mice in each group, and the final average body weight [g] without the tumor).

\section{Acute toxicity test of CTD and CTD-NSVs}

To perform the acute toxicity test of CTD vesicles, we separated 100 mice (half male and half female) weighing 18-20 g each. Before intragastric administration, all mice were fasted for 12 hours, but water was provided. The mice were divided into five groups $(n=10)$. According to the lethal situation in the pretest, we calculated the appropriate toxic dosage of CTD solution and CTD vesicle solution, and thus prepared a series of liquid medicine with different concentrations. We conducted a single intraperitoneal injection with different concentrations of liquid medicine to the animals in each group, and the quantity of administration was $20 \mathrm{~mL} / \mathrm{kg}$. We observed in detail the animal responses within 8 hours after administration. We observed the toxic reactions in animals and death distribution every morning and every afternoon. We continuously observed the mice for 14 days, and weighed them once on a separate day. We also recorded the animals' reactions after administration, including weight changes, diet, appearance, behavior, secretions, excretions, and so on. We conducted an autopsy of dead animals in a timely manner, and conducted gross anatomy of the other animals at the end of the experimental observation period. If diseased organs were
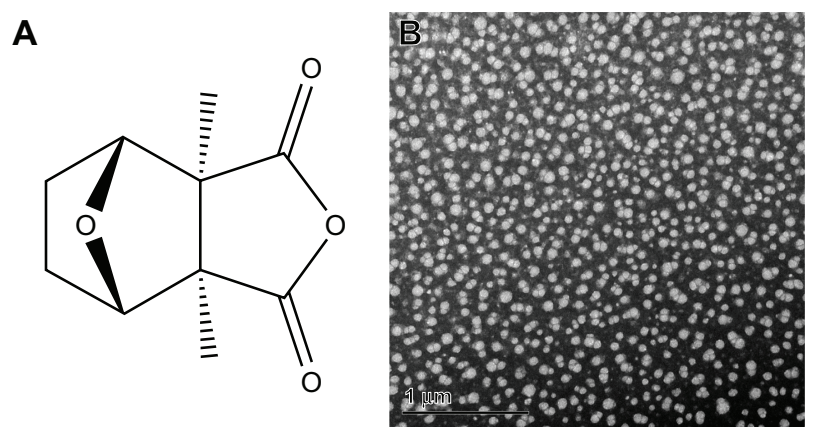

Figure I Chemical structure of cantharidin (A) and transmission electron microscopy image of cantharidin-loaded non-ionic surfactant vesicles (B). 
found, histopathological examination was done. We used the Bliss method to calculate the median lethal dose $\left(\mathrm{LD}_{50}\right)$, for the animals with a $95 \%$ confidence limit.

\section{Liver toxicity experiment of CTD and CTD-NSVs}

Ten healthy Kunming male mice, weighing 25-28 g each as the normal control group, were administered normal saline by peritoneal injection. One hundred and fifty mice for the free CTD group and CTD-NSV group, respectively, were administered once with an intraperitoneal injection dose of $\mathrm{LD}_{50}-0.2 \mathrm{~mL} / 10 \mathrm{~g}$ weight. We drew blood from the orbit of the mice at 1, 3, 5, 24, and 144 hours after administration. Then the serum was centrifuged and the content of alanine aminotransferase (ALT), aspertate aminotransferase (AST), and total bilirubin metabolism (TBIL) were determined.

\section{Statistical analysis}

The results are presented as means \pm standard error. Statistical analysis was performed using Student's $t$-test or one-way analyses of variance. A $P$-value less than 0.05 was considered significant, and a $P$-value less than 0.01 was considered highly significant.

\section{Results and discussion}

\section{In vitro cytotoxicity of free CTD} and CTD-NSVs against breast cancer cells Cellular cytotoxicity assays of blank NSVs, free CTD, and CTD-NSVs were carried out on MCF-7 cells. MTT assay showed that both free CTD and CTD-NSVs significantly suppressed MCF-7 cell proliferation in a dose- and time-dependent manner. At the same concentration, CTD-NSVs showed significantly higher inhibition rates against the $\mathrm{MCF}-7$ cells compared to free $\mathrm{CTD}$
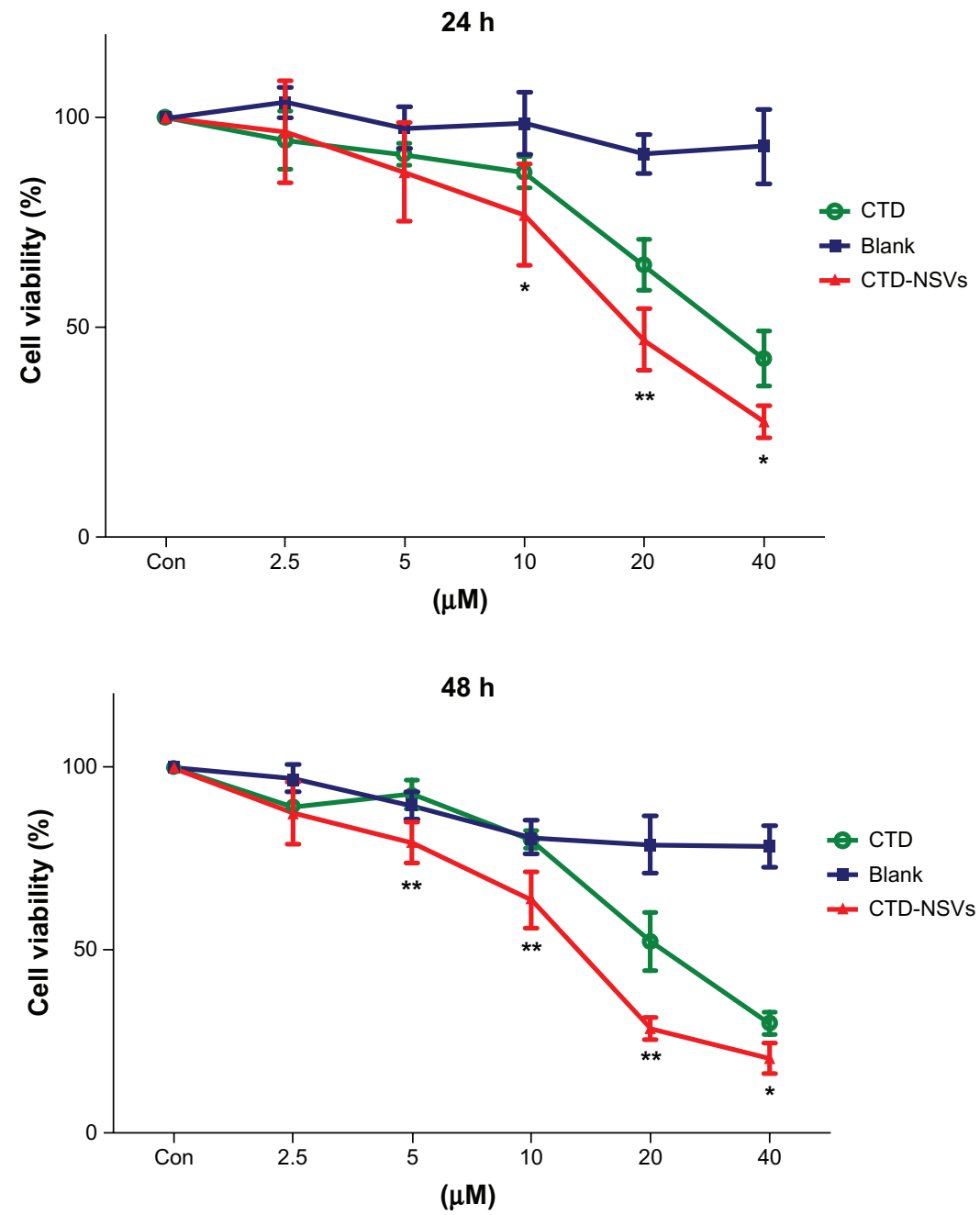

Figure 2 3-(4,5-Dimethylthiazol-2-yl)-2,5-diphenyltetrazolium bromide assay showing that both free cantharidin (CTD) solution and CTD-loaded non-ionic surfactant vesicles (CTD-NSVs) $(0-40 \mu \mathrm{M})$ treatment could inhibit the growth of MCF-7 cells in a time- and dose-dependent manner, while blank NSVs showed negligible effect on cell viability

Notes: Results are expressed as means \pm standard deviation $(n \geq 3)$. $* P<0.05$ and $* * P<0.01$ compared to the same concentration of free CTD solution group. 
solution (Figure 2). Our study showed that the $\mathrm{IC}_{50}$ values of CTD-NSVs $(16.88 \mu \mathrm{M}$ and $11.45 \mu \mathrm{M}$ at 24 and 48 hours, respectively) were much lower than that of free CTD $(31.75 \mu \mathrm{M}$ and $25.59 \mu \mathrm{M}$ at 24 and 48 hours, respectively) at a series of time points. Meanwhile, in all toxicity studies, blank NSVs were taken as respective controls for free CTD and CTD-NSVs. We found that blank NSVs showed negligible effect on cell viability, especially at 24 hours (Figure 2). Therefore, the cytotoxicity effect of CTD-NSVs was primarily attributed to the enhancing effect of CTD.

\section{Cell-cycle analysis}

CTD has already been shown to affect cell-cycle distribution in various kinds of cells. ${ }^{5,6,27}$ Figure 3 shows the cell-cycle histograms of MCF-7 cells treated with CTD-NSVs and
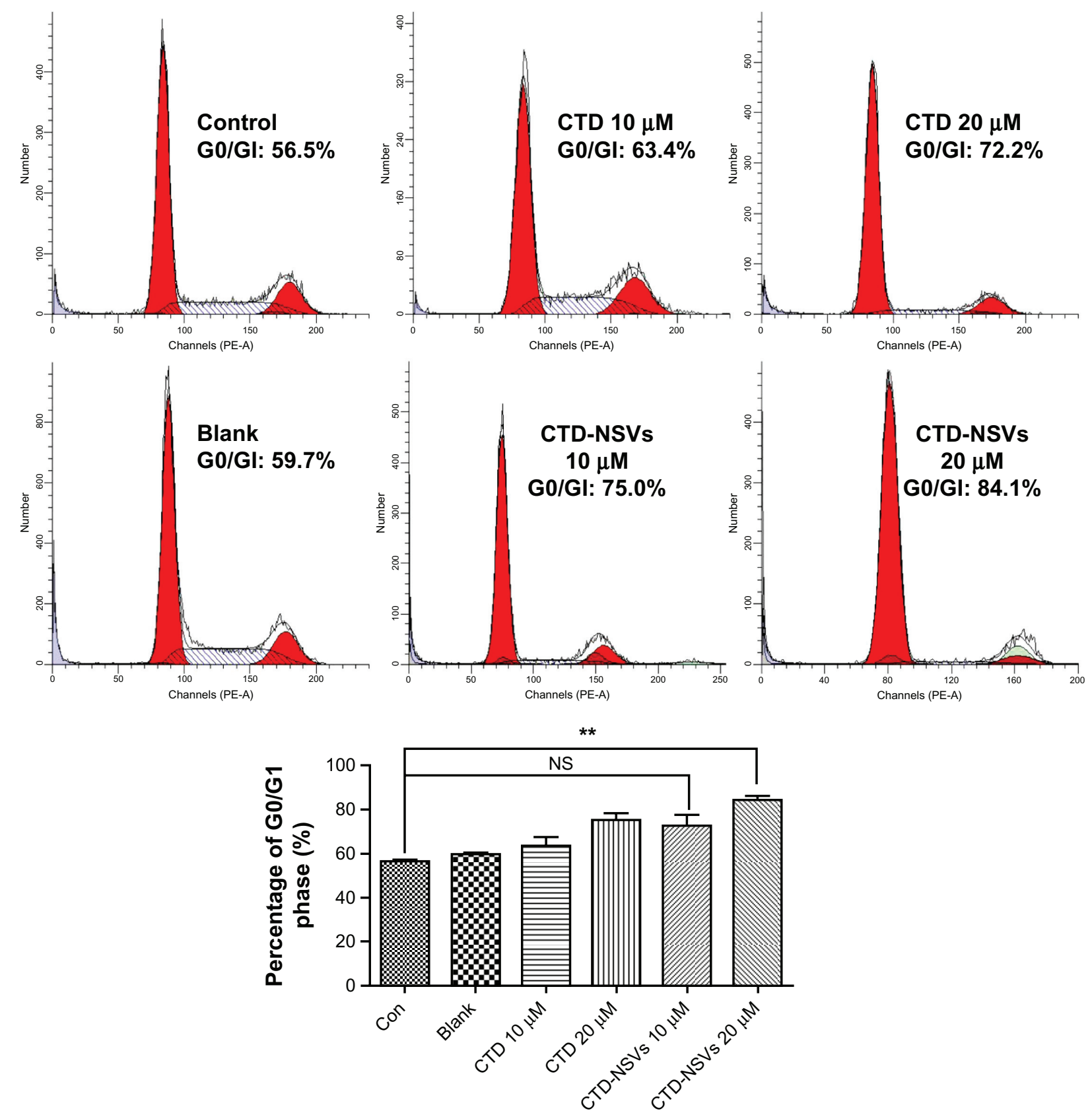

Figure 3 Effects of free cantharidin (CTD) solution, CTD-loaded non-ionic surfactant vesicles (CTD-NSVs) (0, 10, $20 \mu \mathrm{M})$, and blank NSVs on the cell-cycle distribution of MCF-7 cells.

Notes: The various phases of the cell cycle were evaluated by flow cytometry. $20 \mu M$ CTD-NSVs significantly induced cell-cycle arrest at the G0/GI phase, while free CTD solution and blank NSVs showed negligible effect on cell-cycle distribution of MCF-7 cells. Data are expressed as mean \pm standard error of three experiments in duplicate. $* * P<0.01$ compared to control.

Abbreviations: PE-A, pycoerythrin-absorption; NS, not significant; NSVs, non-ionic surfactant vesicles. 
CTD solution at different concentrations $(0,10,20 \mu \mathrm{M})$ for 24 hours. The flow cytometry assay showed that CTD-NSVs and CTD solution arrested MCF-7 cells at the G0/G1 phase in a dose-dependent manner. Following exposure to CTD solution and CTD-NSVs at $10 \mu \mathrm{M}$ for 24 hours, the percentage of cells in the $\mathrm{G} 0 / \mathrm{G} 1$ phase were $63.4 \%$ and $75.0 \%$, respectively, both higher than that of the control group (56.5\%). When the concentration increased to $20 \mu \mathrm{M}$, the fraction of cells in the $\mathrm{G} 0 / \mathrm{G} 1$ phase rose to $72.2 \%$ and $84.1 \%$, respectively. In our study, only $20 \mu \mathrm{M}$ CTD-NSVs significantly arrested MCF-7 cells at the G0/G1 phase $(P<0.01)$. Meanwhile, we found that blank NSVs showed a negligible effect on cell-cycle distribution. These data suggested that NSVs could enhance the cell-cycle arrest effect of CTD in MCF-7 cells.

\section{Cell-apoptosis observation}

Apoptosis is the programmed process that is essential for the development of most metazoans, and deregulation of apoptosis is an indicator of most cancer cells. ${ }^{28}$ CTD was previously reported to induce apoptosis in several kinds of cancer cells. ${ }^{3,7}$ Based on the cell-cycle analysis, we further characterized CTD/CTD-NSVs induced apoptosis by Hoechst 33342 staining. As shown in Figure 4, MCF-7 cell nuclei were round and homogeneously stained in control and blank NSV groups; however, after being treated with
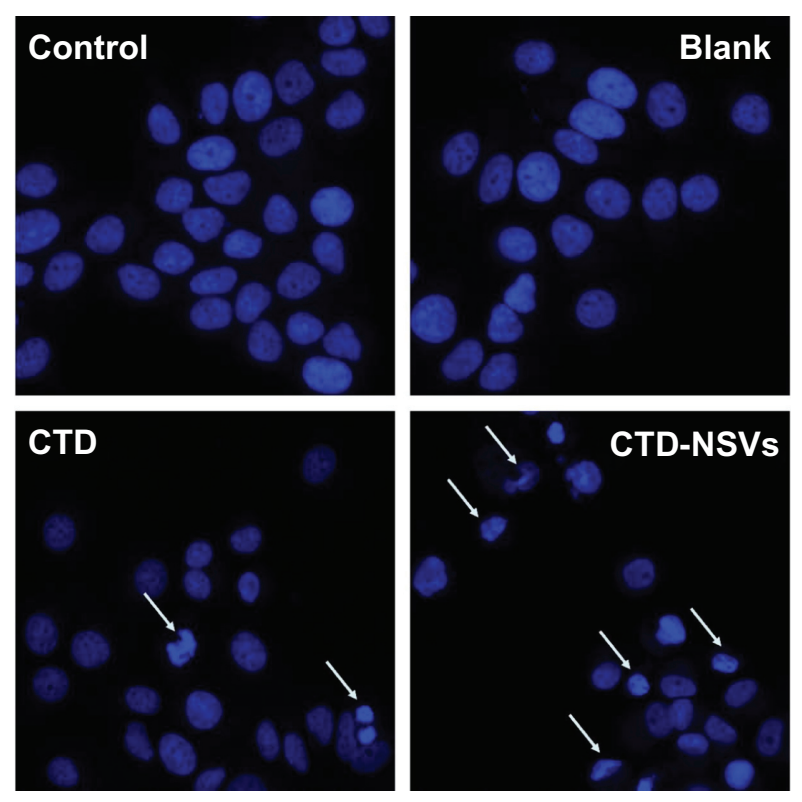

Figure 4 Hoechst 33342 fluorescent staining to detect apoptotic morphology in breast cancer cells.

Notes: MCF-7 cells were treated with blank non-ionic surfactant vesicles (NSVs), free cantharidin (CTD) $(20 \mu \mathrm{M})$, and CTD-NSVs $(20 \mu \mathrm{M})$ for 48 hours. Cells were observed in three experiments using a fluorescent microscope (Olympus, Tokyo, Japan). Abbreviation: CTD-NSVs, CTD-loaded non-ionic surfactant vesicles.
$20 \mu \mathrm{M}$ CTD for 48 hours, cells showed marked nuclei condensation. In addition, the partition of cytoplasm and nucleus into membrane-bound vesicles (apoptotic bodies) was also observed. The CTD-NSV group showed nearly twice the apoptotic rates compared to free CTD. Meanwhile, we found that blank NSVs showed a negligible effect on cell nucleus change. The morphological changes of cell nuclei indicated that the apoptosis-inducing effects of CTD might be significantly enhanced by NSVs.

\section{CTD-NSVs significantly inhibited tumor growth in vivo}

We selected $\mathrm{S}_{180}$ tumor-bearing mice as animal models, because this has been one of the classic tumor models for quite some time and was introduced in the antitumor studies on CTD. ${ }^{29,30}$ The inhibitory action of different formulations of CTD against $\mathrm{S}_{180}$ solid tumor in mice is shown in Figure 5A. We found that the NSV-enhanced in vivo anticancer efficacy in $\mathrm{S}_{180}$ solid tumor mice was consistent with the in vitro effects. After 10 days, no decrease in body weight was observed in any of the four groups. The negative control group of 20 mice injected with saline solution induced an average tumor weight of $2.516 \pm 0.461 \mathrm{~g}$. For mice treated with $35 \mathrm{mg} / \mathrm{kg}$ of cyclophosphamide, the tumor suppression was obvious, with a mean tumor weight of $1.504 \pm 0.540 \mathrm{~g}$, which was significantly smaller than that of the control group. Compared with the controls, the tumor-inhibition rates in high- $(1.0 \mathrm{mg} / \mathrm{kg})$, medium- $(0.5 \mathrm{mg} / \mathrm{kg})$, and low(0.25 mg/kg)-dose CTD-treated mice were 31.05\%, 29.84\%, and $26.92 \%$, respectively. Interestingly, when the mice were treated with CTD-NSVs, a relatively high tumor-inhibition rate $(52.76 \%)$ was observed in the high-dose group, which was significantly higher than that of the free CTD at the same dose. For the medium- and low-dose group, no significant difference was observed between the two formulations of CTD. In addition, the spleen index in the cyclophosphamide and all free CTD dose groups was significantly lower than that of the model control group (Figure 5B). In the highdose group of CTD-NSVs, the spleen index increased and was significantly higher than that of the free CTD at the same dose. No significant differences in thymic index were observed in all groups.

\section{CTD-NSVs exhibited lower toxicity in vivo}

The clinical signs of CTD poisoning indicate that toxicity (especially hepatotoxicity) is still the largest challenge for further clinical application. ${ }^{31,32}$ In the present study, after 

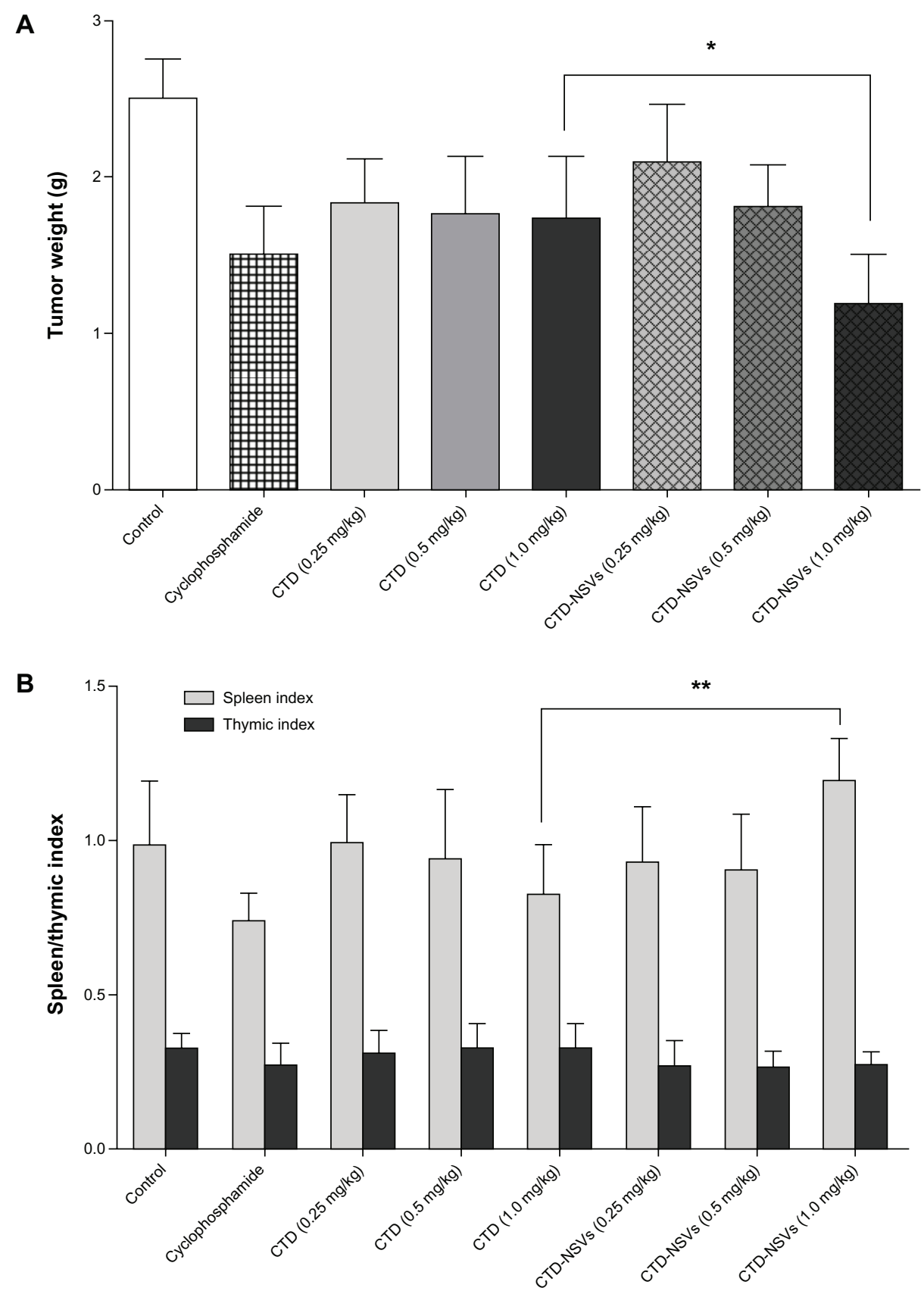

Figure 5 Effects of cantharidin (CTD) and CTD-loaded non-ionic surfactant vesicles (CTD-NSVs) on tumor weight (A), spleen and thymic index (B) against $\mathrm{S}_{180}$ xenograftbearing mice.

Notes: Data are expressed as means \pm standard error. $* P<0.05$ and $* * P<0.01$ compared to the same concentration in the free CTD solution group.

intraperitoneal injection of CTD solution for 30 minutes, the activities of the mice became slow and toxic responses including abdominal pain, listlessness, and dropped surface temperature. Some mice died after 3 hours. Interestingly, for mice injected with CTD-NSVs, all toxic responses and death were postponed to 1-2 hours and 8-12 hours after injection, respectively. Meanwhile, calculated by the Bliss method, we also found that the $\mathrm{LD}_{50}$ value of CTDNSVs $(5.42 \mathrm{mg} / \mathrm{kg}$ ) was much lower than that of free CTD
$(2.64 \mathrm{mg} / \mathrm{kg})$, which indicates significantly lower acute toxicity (Figure 6A).

The liver is known to be the main organ for detoxifying and metabolizing xenobiotics. ALT and AST are important enzymes in the liver, and their concentrations are usually closely related to chronic liver diseases. ${ }^{33}$ To evaluate whether CTD-NSVs resulted in lower hepatotoxicity than free CTD in vivo, mice were injected with free CTD or CTD-NSVs, and serum ALT, AST, and TBIL levels were detected. The AST, 

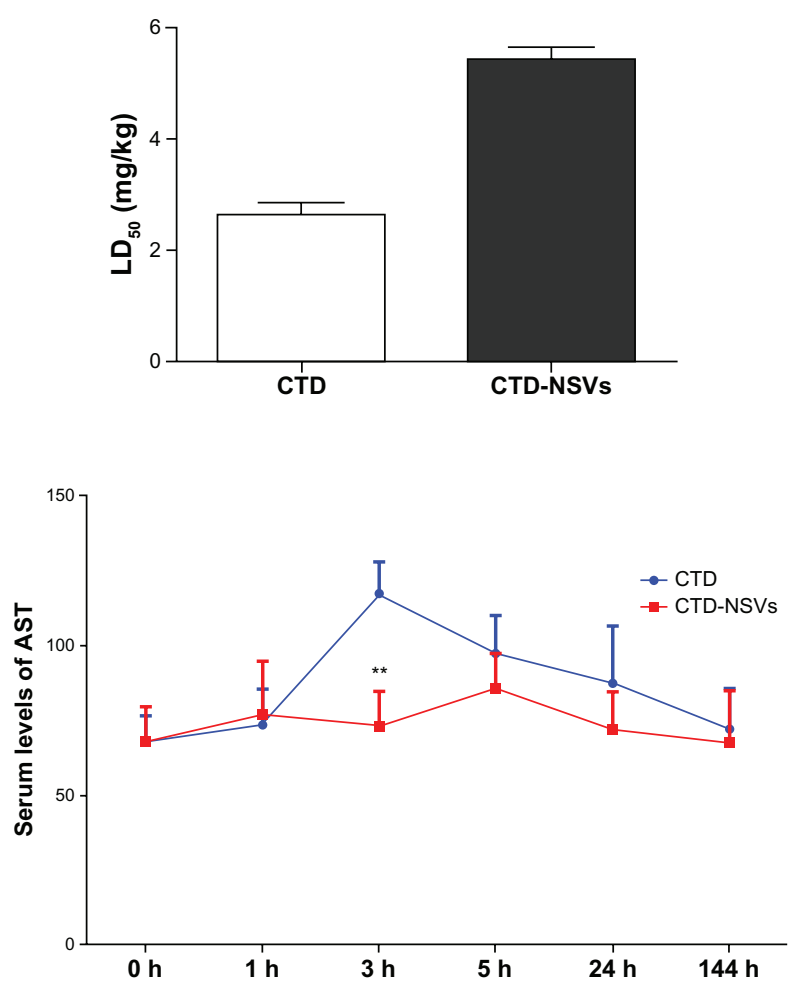
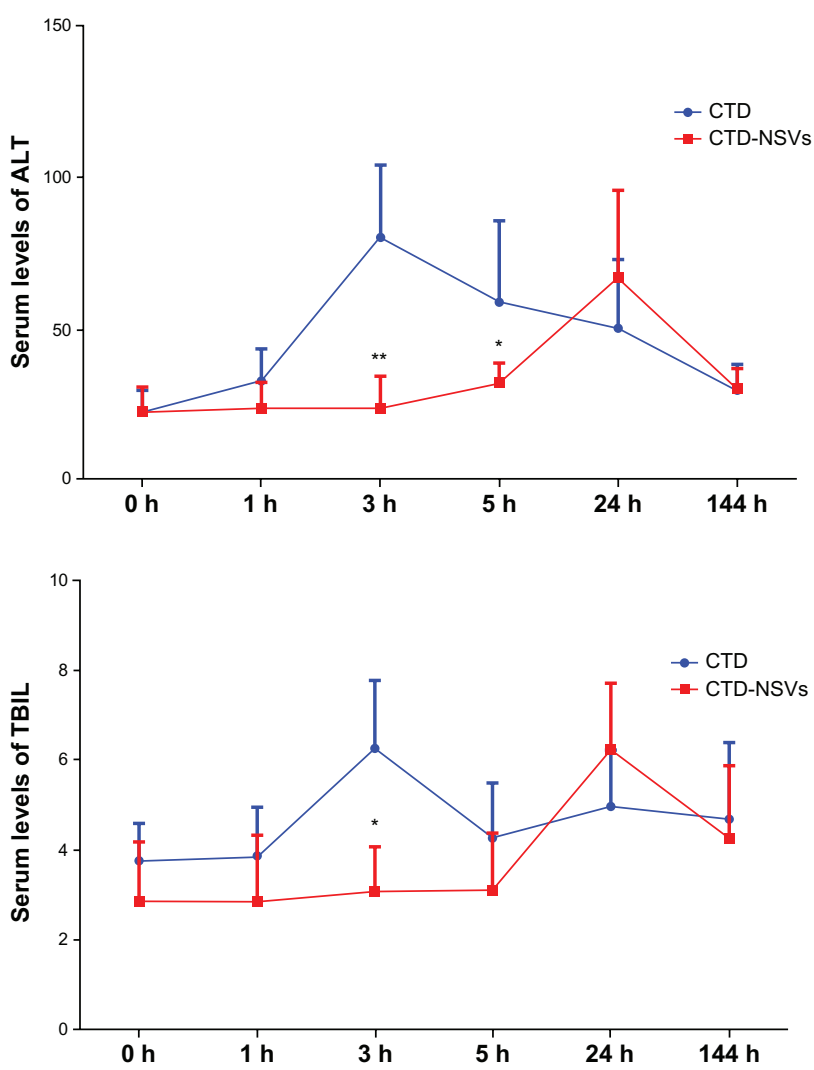

Figure 6 Median lethal dose $\left(\mathrm{LD}_{50}\right)$, serum alanine aminotransferase (ALT), aspartate transaminase (AST), and total bilirubin (TBIL) level of mice after treatment with cantharidin (CTD) and CTD-loaded non-ionic surfactant vesicles (CTD-NSVs).

Notes: Data are expressed as means \pm standard error. $* P<0.05$ and $* * P<0.01$ compared to the same concentration of free CTD solution group.

ALT, and TBIL levels of the CTD-treated mice were all increased compared to the control group, indicating significant liver damage caused by CTD (Figure 6). However, all the three values in the CTD-NSV group were significantly lower than that of the CTD group (except for 24 hours). Moreover, in viewing the level of serum ALT, AST, and TBIL, liver toxicity of the CTD-NSV group appeared significantly slower compared to the CTD group, which is consistent with acute toxic responses, such as abdominal pain and listlessness. The highest levels of ALT, AST, and TBIL in free CTD group all appeared at 3 hours after injection, whereas the highest ALT and TBIL levels of CTD-NSVs group were at 24 hours. Our results demonstrated that liver toxicity induced by CTD was weakened via NSV encapsulation.

\section{Conclusion and discussion}

There are many kinds of Mylabris-based pharmaceutical preparations in the Chinese market, including compound Mylabris injection, compound Mylabris capsules, and Qinin (CTD sodium) injection, in which CTD is considered the major active component. In clinical therapeutics, cantharidin is largely limited by its short half-life and toxicity. ${ }^{34}$ There exists an urgent necessity to develop an efficient delivery system to reduce liver toxicity, membrane irritation, and improve the drug's anticancer efficacy. Compared to phospholipid-based vesicles such as liposomes, NSVs have advantages of chemical stability, lower toxicity, improved therapeutic performance, and easier handling and storage. NSVs are also relatively low-cost, and their preparation for routine and large-scale production can be performed without using pharmaceutically unacceptable solvents. ${ }^{35}$ For CTD, carriers with lower side effects and high encapsulating capacity is preferred. NSV structural properties allow the entrapment of CTD almost completely in the bilayer, which can minimize degradation and inactivation after administration, prevent undesirable side effects, and increase drug bioavailability and targeting to tumor sites. ${ }^{36}$ Therefore, in this study, we developed CTD-NSVs (noisomes) and evaluated their potential in enhancing in vitro and in vivo antitumor activities and reducing CTD's toxicity.

Our in vitro toxicity studies confirmed that NSVs could significantly facilitate the cytotoxic actions of CTD. Generally, nanoparticles can be internalized into cells by endocytosis, phagocytosis, or just being adsorbed onto the 
surface of the cells. ${ }^{37}$ The enhanced toxicity of CTD may be mainly attributed to accelerated cellular uptake, because NSVs could be nonspecifically internalized into cells via endocytosis or phagocytosis. Moreover, by markedly increasing the solubility and dissolution rate of CTD, NSVs could produce higher molecular concentration around the cells. The increased in vitro antitumor effects may also be associated with interactions between NSVs and cell membranes, through which membrane permeability may be altered.

Interestingly, CTD treatment alone $(0.25,0.5$, and $1.0 \mathrm{mg} / \mathrm{kg}$ ) produced a reduction of tumor weight to the same extent, while it was notable that CTD-NSVs decreased tumor weight in a concentration-dependent manner (Figure 5A). Due to its poor bioavailability, free CTD may just partially reach the tumor site and penetrate, while encapsulation of CTD into NSVs could increase its penetration in tumors. Although the dose of CTD increased, the content in the target tumor may not subsequently increase. While for CTD-NSVs, higher drug content in tumor can attain based on the enhanced permeability and retention of tumors with leaky vasculature, thus a dose-dependent inhibition on tumor growth could be achieved. The increased content in tumor also indicated that less CTD is distributed throughout the body, consequently reducing the toxicity. These results indicated that cancer therapies based on NSVs can provide improved drug efficacy without increasing the chemotherapeutic drug dose and also through reducing systemic toxicity.

In conclusion, CTD-NSVs presented significant antitumor activity and lower toxicity for the treatment of cancer. MTT assay, cell-cycle analysis, and Hoechst 33342 staining showed that NSVs could enhance the in vitro anticarcinogenic effect of CTD against MCF-7 cells. NSVs also enhanced in vivo anticancer efficacy in $\mathrm{S}_{180}$ solid-tumor mice, which was consistent with the in vitro effects. In addition, the acute toxicity and liver toxicity of CTD were also distinctly decreased via encapsulating into NSVs. Based on these results, we can conclude that NSVs could be a promising delivery system for enhancing antitumor activity and simultaneously reducing the toxicity of CTD. However, this study is lacking in clear understanding of how CTD-NSVs work at cellular and molecular levels, which still deserves further research.

\section{Acknowledgments}

This study was supported by the Research Fund of The Ministry of Science and Technology (2009zx0930-005-05) and Fund of State Administration of TCM (200907001-5), the Macao Science and Technology Development Fund (077/2011/A3, 074/2012/A3), and the Research Fund of the
University of Macau (SRG025-ICMS13-CMW) and (MYRG 208 (Y3-L4)-ICMS11-WYT).

\section{Disclosure}

The authors report no conflicts of interest in this work.

\section{References}

1. Wang S, Wu X, Tan M, et al. Fighting fire with fire: poisonous Chinese herbal medicine for cancer therapy. J Ethnopharmacol. 2012;140(1): 33-45.

2. Wang GS. Medical uses of Mylabris in ancient China and recent studies. J Ethnopharmacol. 1989;26(2):147-162.

3. Rauh R, Kahl S, Boechzelt H, Bauer R, Kaina B, Efferth T. Molecular biology of cantharidin in cancer cells. Chin Med. 2007;2:8.

4. Knapp J, Boknik P, Huke S, et al. Contractility and inhibition of protein phosphatases by cantharidin. Gen Pharmacol. 1998;31(5):729-733.

5. Kuo JH, Chu YL, Yang JS, et al. Cantharidin induces apoptosis in human bladder cancer TSGH 8301 cells through mitochondria-dependent signal pathways. Int J Oncol. 2010;37(5):1243-1250.

6. Huang WW, Ko SW, Tsai HY, et al. Cantharidin induces G2/M phase arrest and apoptosis in human colorectal cancer colo 205 cells through inhibition of CDK1 activity and caspase-dependent signaling pathways. Int J Oncol. 2011;38(4):1067-1073.

7. Liu D, Chen Z. The effects of cantharidin and cantharidin derivates on tumour cells. Anticancer Agents Med Chem. 2009;9(4):392-396.

8. Zhang WD, Zhao HR, Yan Y, Wang XH, Zong ZH, Liu Y. Apoptosis induced by cantharidin in human pulmonary carcinoma cells A549 and its molecular mechanisms. Zhonghua Zhong Liu Za Zhi. 2005;27(6): 330-334. Chinese.

9. Bonness K, Aragon IV, Rutland B, Ofori-Acquah S, Dean NM, Honkanen RE. Cantharidin-induced mitotic arrest is associated with the formation of aberrant mitotic spindles and lagging chromosomes resulting, in part, from the suppression of PP2A alpha. Mol Cancer Ther. 2006;5(11):2727-2736.

10. Zhang C, Peng Y, Wang FC, et al. A synthetic cantharidin analog for the enhancement of doxorubicin suppression of stem cell-derived aggressive sarcoma. Biomaterials. 2010;31(36):9535-9543.

11. Yeh CB, Su CJ, Hwang JM, Chou MC. Therapeutic effects of cantharidin analogues without bridging ether oxygen on human hepatocellular carcinoma cells. Eur J Med Chem. 2010;45(9):3981-3985.

12. Thaqi A, Scott JL, Gilbert J, Sakoff JA, McCluskey A. Synthesis and biological activity of delta-5,6-norcantharimides: importance of the 5,6-bridge. Eur J Med Chem. 2010;45(5):1717-1723.

13. Chang CC, Liu DZ, Lin SY, et al. Liposome encapsulation reduces cantharidin toxicity. Food Chem Toxicol. 2008;46(9):3116-3121.

14. Carafa M, Santucci E, Lucania G. Lidocaine-loaded non-ionic surfactant vesicles: characterization and in vitro permeation studies. Int J Pharm. 2002;231(1):21-32.

15. Di Marzio L, Marianecci C, Petrone M, Rinaldi F, Carafa M. Novel pHsensitive non-ionic surfactant vesicles: comparison between Tween 21 and Tween 20. Colloids Surf B Biointerfaces. 2011;82(1):18-24.

16. Cosco D, Paolino D, Muzzalupo R, et al. Novel PEG-coated niosomes based on bola-surfactant as drug carriers for 5-fluorouracil. Biomed Microdevices. 2009;11(5):1115-1125.

17. Marianecci C, Paolino D, Celia C, Fresta M, Carafa M, Alhaique F. Non-ionic surfactant vesicles in pulmonary glucocorticoid delivery: characterization and interaction with human lung fibroblasts. $J$ Control Release. 2010;147(1):127-135.

18. Alam M, Dwivedi V, Khan AA, Mohammad O. Efficacy of niosomal formulation of diallyl sulfide against experimental candidiasis in Swiss albino mice. Nanomedicine (Lond). 2009;4(7):713-724.

19. Li H, Fang Q, Zhang H, et al. Preparation and characterization of non-ionic surfactant vesicle of cantharidin. Zhongguo Zhong Yao Za Zhi. 2010;35(19):2546-2550. Chinese. 
20. Scudiero DA, Shoemaker RH, Paull KD, et al. Evaluation of a soluble tetrazolium/formazan assay for cell growth and drug sensitivity in culture using human and other tumor cell lines. Cancer Res. 1988;48(17): 4827-4833.

21. Zhong Z, Chen X, Tan W, et al. Germacrone inhibits the proliferation of breast cancer cell lines by inducing cell cycle arrest and promoting apoptosis. Eur J Pharmacol. 2011;667(1-3):50-55.

22. Wang S, Chen T, Chen R, Hu Y, Chen M, Wang Y. Emodin loaded solid lipid nanoparticles: preparation, characterization and antitumor activity studies. Int J Pharm. 2012;430(1-2):238-246.

23. Gao JL, He TC, Li YB, Wang YT. A traditional Chinese medicine formulation consisting of Rhizoma Corydalis and Rhizoma Curcumae exerts synergistic anti-tumor activity. Oncol Rep. 2009;22(5): 1077-1083.

24. Zhong ZF, Li YB, Wang SP, et al. Furanodiene enhances tamoxifeninduced growth inhibitory activity of ERa-positive breast cancer cells in a PPARgamma independent manner. J Cell Biochem. 2012;113(8): 2643-2651.

25. Li YB, Lin ZQ, Zhang ZJ, et al. Protective, antioxidative and antiapoptotic effects of 2-methoxy-6-acetyl-7-methyljuglone from Polygonum Cuspidatum in PC12 cells. Planta Med. 2011;77(4):354-361.

26. Hong M, Zhu S, Jiang Y, Tang G, Pei Y. Efficient tumor targeting of hydroxycamptothecin loaded PEGylated niosomes modified with transferrin. J Control Release. 2009;133(2):96-102.

27. Sakoff JA, Ackland SP, Baldwin ML, Keane MA, McCluskey A. Anticancer activity and protein phosphatase 1 and $2 \mathrm{~A}$ inhibition of a new generation of cantharidin analogues. Invest New Drugs. 2002;20(1): $1-11$.

28. Kang N, Zhang JH, Qiu F, Tashiro S, Onodera S, Ikejima T. Inhibition of EGFR signaling augments oridonin-induced apoptosis in human laryngeal cancer cells via enhancing oxidative stress coincident with activation of both the intrinsic and extrinsic apoptotic pathways. Cancer Lett. 2010;294(2):147-158.
29. Gao Z, Jiang P, Xiong H. Experimental study on anti-cancer effect of cantharidine derivatives and platinum complex. Zhongguo Zhong Xi Yi Jie He Za Zhi. 1999;19(1):37-39. Chinese.

30. Jiang Y, Jiang X, Law K, et al. Enhanced anti-tumor effect of 9-nitrocamptothecin complexed by hydroxypropyl-beta-cyclodextrin and safety evaluation. Int J Pharm. 2011;415(1-2):252-258

31. Moed L, Shwayder TA, Chang MW. Cantharidin revisited: a blistering defense of an ancient medicine. Arch Dermatol. 2001;137(10): 1357-1360.

32. Graziano MJ, Waterhouse AL, Casida JE. Cantharidin poisoning associated with specific binding site in liver. Biochem Biophys Res Commun. 1987;149(1):79-85.

33. Ozer JS, Chetty R, Kenna G, et al. Enhancing the utility of alanine aminotransferase as a reference standard biomarker for drug-induced liver injury. Regul Toxicol Pharmacol. 2010;56(3):237-246.

34. Dang YJ, Zhu CY. Oral bioavailability of cantharidin-loaded solid lipid nanoparticles. Chin Med. 2013;8(1):1.

35. Di Marzio L, Esposito S, Rinaldi F, Marianecci C, Carafa M. Polysorbate 20 vesicles as oral delivery system: in vitro characterization. Colloids Surf B Biointerfaces. 2013;104:200-206.

36. Marianecci C, Rinaldi F, Mastriota M, et al. Anti-inflammatory activity of novel ammonium glycyrrhizinate/niosomes delivery system: human and murine models. J Control Release. 2012;164(1):17-25.

37. des Rieux A, Fievez V, Garinot M, Schneider YJ, Preat V. Nanoparticles as potential oral delivery systems of proteins and vaccines: a mechanistic approach. J Control Release. 2006;116(1):1-27.
International Journal of Nanomedicine

\section{Publish your work in this journal}

The International Journal of Nanomedicine is an international, peerreviewed journal focusing on the application of nanotechnology in diagnostics, therapeutics, and drug delivery systems throughout the biomedical field. This journal is indexed on PubMed Central, MedLine, CAS, SciSearch $\AA$, Current Contents ${ }^{\circledR} /$ Clinical Medicine,

\section{Dovepress}

Journal Citation Reports/Science Edition, EMBase, Scopus and the Elsevier Bibliographic databases. The manuscript management system is completely online and includes a very quick and fair peer-review system, which is all easy to use. Visit http://www.dovepress.com/ testimonials.php to read real quotes from published authors. 